\title{
A NEW APPROACH TO THE APPLICATION OF THE PRINCIPLES OF SUSTAINABLE DEVELOPMENT
}

\author{
Inese Trusina1, PhD student; Elita Jermolajeva2, Dr.oec., Senior Researcher
}

1, 2 Latvia University of Life Sciences and Technologies

\begin{abstract}
Most of the environmental, economic, social and political problems that have given rise to the global crisis continue to grow negatively and rapidly. It is with this situation that the world community has faced, feeling the consequences of earlier decisions. It is natural to raise the question: why, despite enormous efforts, it is not possible to reverse the negative trends and ensure the transition to sustainable development of the world community. In order for the criteria of sustainable development to meet these requirements, it is necessary to determine the main governing laws and find a way to measure different quality social, natural processes and resource flows in stable and universal units of measurement (measures). The article presents the basic definitions for the development of a formalized description of the tasks of monitoring sustainable development that meets the principles and requirements of sustainable development. It provides examples of calculating the parameters of sustainable development of Latvia and their primary interpretation. To formalize the tasks of sustainable development, the authors considered the methodology of systems analysis, methods of managing sustainable development projects using the concept of flows of full and useful power in open non-equilibrium stable systems, flows model of interactions in the system 'man - society - nature', as well as the theory of a unified system of space-time measurements. The main conclusions are: the system of four universal indicators of sustainable development shows that by 2019 the system of Latvia had a trend towards non-sustainable development. A decrease in consumption indicates an extensive development and is the result of a decrease in population, and is not associated with improving the structure of resource consumption and their efficient use.
\end{abstract}

Key words: sustainable development, sustainable development goals, spatial-temporal approach, indicators.

JEL code: E19, F69, Q59, R10

\section{Introduction}

The International Conference held in 2012 in Rio de Janeiro reaffirmed that the world is in a systemic crisis (Rio+20, 2012). Most of the environmental, economic, social and political problems that have given rise to the global crisis continue to grow negatively and rapidly. If there is no natural-scientific solution to this problem, then there can be no adequate political solution. The world community has faced with this situation, feeling the consequences of earlier decisions. It is obvious that over 40 years, especially at the beginning of the $21^{\text {st }}$ century, world development has become more unstable, chaotic, turbulent, bringing suffering to billions of people.

Most of the problems that the world community has faced are associated not only with a lack of resources, but with a violation of fundamental laws. World Business Council for Sustainable Development (WBSCD, 2010) experts have shown that society is forced to make decisions based on biased information. The bias is due to the lack of adequate methodology and technology for measuring sustainable development. This is confirmed by analysing the list of criteria to estimate sustainable development (Hak, T. et al., 2016):

1) increase the ability to meet the needs of present and future generations;

2) preserve the natural resource potential;

3) increase the level of integration the economy and the environment;

4) preserve the biosphere and the survival of the human race;

5) enhance the growth the productive forces and an increase the level of well-being of the population;

6) preserve the balance of social justice, environmental safety and economic efficiency;

7) preserve the balance of consumption and reproduction of natural resources; 

8) reduce of anthropogenic impact on the biosphere;
9) enhance the development of the spiritual principle in every person.

The WBSCD (WBSCD, 2010) experts have shown that all the above criteria for sustainable development do not meet the general system requirements as well as SMART parameters of goals (Specific, Measurable, Achievable, Realistic, and Timely).

In September 2015 in New York the United Nations (UN) meeting adopted the Sustainable Development Goals (SDGs), officially known as Transforming our world: the 2030 Agenda for Sustainable Development - a set of goals for future international cooperation that replaced the Millennium Development Goals at the end 2015 year. These goals are planned to be achieved from 2015 to 2030. The final document contains 17 global goals and 169 corresponding targets and 265 indicators (Agenda 2030, 2015).

It should be noted that this document states that the Concept of Sustainable Development emerged in the process of combining three main points of view: economic, social and environmental. This implies the adoption of measures aimed at the optimal use of limited resources and the use of environmentally friendly - nature, energy, and material-saving technologies, to maintain the stability of social and cultural systems, to ensure the integrity of biological and physical natural systems. It is assumed that the achievement of the SDGs will be carried out in accordance with the following provisions:

1) countries will independently develop their own strategies of sustainable development. The SDGs will act as a benchmark;

2) achievement of the SDGs will be monitored and tracked using the Global Indicator Set;

3) monitoring and review the results and means of SDG implementation will be organized.

The UN and the countries of the world are actively promoting the ideas of sustainable development. And, nevertheless, the problem is not dying out, but on the contrary it is getting worse. Decisions are not aligned with the laws of nature and cannot be controlled. All this indicates that the problem cannot be solved by the means used (Lele, S., 1991, Pogge, T., 2015). By 2021, humanity has not managed to eliminate any of the global dangers. Declaring its commitment to the principles of sustainable development, it has acquired a set of new risks and challenges. The question arises: why, despite enormous efforts, it is impossible to change negative trends and ensure the transition of the world community to sustainable development.

The purpose of the article is to review new approaches and methodologies the concept of sustainable development that could meet the new requirements of society, be able to determine the main regulatory laws and find ways to measure various qualitative socio-economic and natural processes in stable and universal units of measurement (measures).

\section{Theoretical findings}

\subsection{New philosophy of sustainable development}

Humanity has come to a point where special responsibility, rationality in decisions and actions, considering national interests and the needs of the world community are required. It is necessary to get rid of the causes that give ri9se to conflicts, wars, hunger, poverty, disease, illiteracy, destruction of the natural environment. It is necessary to create conditions that ensure the sustainability of the development of the world on a scientific, reasonable basis. Society has entered an era when knowledge of these laws and their skilful use have become a necessity. As the power of humanity grows, its responsibility for each step taken must increase. Humanity has become a powerful global geological force. Domination over nature should consist in the ability to cognize its laws and use them for the good, to be able to use these laws as 
an objective criterion for collective reason and the effectiveness of one's practical activity. A direct continuation of this classical thought is the teaching of Vernadsky V. (2006) about the restructuring of the biosphere into the noosphere - a qualitatively new state, which is a historically inevitable process.

On a planetary scale, the noosphere means social and natural integrity, the defining link of which is the human mind, which cognizes and correctly applies the general laws of nature in order to ensure sustainable development in the "nature-society-human" system. The main function of the noospheres' world is to ensure such a course of the world historical process that guarantees the stability of its development on the basis of the implementation of general laws in their mutual internal connection. Due to this, the rate of formation of the noospheres' world entirely depends on scientific knowledge and the ability to correctly apply general laws in social practice, and the time of its formation is determined by the period of mankind's mastery of these laws.

The social-economy system is a subsystem and embedded in nature system, and economic processes are natural processes as biological, physical and chemical processes and transformations. Therefore, the economy ought to be studied also, but not only, as a natural object, as well as economic processes should also be conceptualized in terms usually used to describe processes in nature (Ropke, I., 2004).

\subsection{Live open non-equilibrium systems}

One of the reasons for the slowdown in the transition to sustainable development is sought in technological imperfection and possible technological deadlock. It should be noted that most of the technologies of the $20^{\text {th }}$ century is based on laws that are valid for energy-closed systems. Naturally, the 'waste' generated as a result of the use of such technologies turns out to be, as it were, 'outlawed' and for this reason they turn out to be unaccounted for in the technological design - they require additional costs to increase the efficiency of technologies.

It should be noted, that in accordance with the definitions of the natural sciences, all living things nature and society - are open stable non-equilibrium systems. And therefore, it is natural to use the laws of living systems for the creation of technologies for sustainable development. There is not a single closed living system in Nature, which has no inflows and outflows of energy, and the power (changes in the amount of energy or flow) would be equal to zero. The law of conservation of energy is valid only for systems closed in energy flows and cannot serve as an adequate measure of open - living systems.

Economic and ecological systems are conceptualized in the same language of energy and matter flows, and this confirms that the human economy is embedded in the Earth's biosphere (Ropke, I., 2004). This means what Daly H. E. calls the preanalytical vision of ecological economics: the human economy is an open system within the structure of a closed system in the thermodynamic sense (Daly, H., 1980). The human economy exchanges matter and energy with the larger system of the Earth. The earth receives solar energy from the outside and emits heat, and this energy flow supports the processes in the system.

Currently, inconsistency or incoherence of measures of heterogeneous (social, economic, ecological, etc.) systems is the reason for the rupture of ties, the reason leading to the fact that social systems are controlled in isolation from the general laws of living systems, which ultimately leads to a global systemic crisis. It is possible to eliminate this gap by establishing a measure that expresses the essence of living systems. According to Bauer E. S. (2002), it is characteristic of living systems that they, due to their free energy, perform work against the expected equilibrium. Based on the principle of stable non-equilibrium, the main property of energy flows circulating in living systems is their ability to perform external useful work or working capacity or to have the useful power. 


\subsection{Human role and impact}

What is the cause and driving force of the non-decreasing growth of human capabilities Podolinsky S. (2004) showed that man is the only known force of nature in science, which, by certain volitional acts, is capable of: 1 . increasing the share of the Sun's energy accumulated on the Earth's surface; 2 . to reduce the amount of energy dissipated into world space. Plants that accumulate radiant energy into the substance of their own body cannot convert it into movement, and animals, from the simplest to the highest (not including humans), cannot spend it in such a way as to increase the amount of accumulated energy. Only a human with his labour, applying new machines and technologies, achieves this goal (Aleksejeva, L. et al., 2020). Thus, through labour and scientific thought, a person is included in the biospheres' circulation of matter and energy. This determines the place of labour and reason in the natural-historical process of the evolution of the biosphere. This determines the mission of Human on planet Earth.

\section{Methodology}

\subsection{New old definition of sustainable development}

Based on the previously formulated provisions of the concept 'sustainable development', it can be determined that "Sustainable development is a continuous process of preserving the increasing of opportunities to meet the constant existing needs of the system, expressed in units of power. The goal sustainability- are achieved by development the quality of planning and introducing innovations that ensure a steady growth in the efficiency of resource use, as well as an increase in income without an increase in the rate of their consumption, as well as a decrease in losses in conditions of negative external and internal influences (Bolshakov, B. et al., 2019).

Power is a scalar physical quantity that is generally equal to the rate of change, conversion, transmission or consumption of energy in the system. More specifically, the power is equal to the ratio of the work done in a given period of time to that period of time. The definition of 'sustainable development' includes two aspects (Fig. 1):

1) preservation - increasing opportunities to meet needs both today and in the future;

2) development - changes due to the state of technology and organization of society, the imposed ability to meet needs.

The sustainable development of social-economic system is supported by the following main factors (Shamaeva, E., 2019): 1) increasing the efficiency of technologies; 2) increasing the efficiency of resource use; 3 ) increasing the efficiency of flow management.

If the growth of the power of the system (the growth of the flow of free energy) is provided not due to the indicated factors but due to the growth of total energy consumption, then there is not the development of the system of social production, and there is extensive growth. 


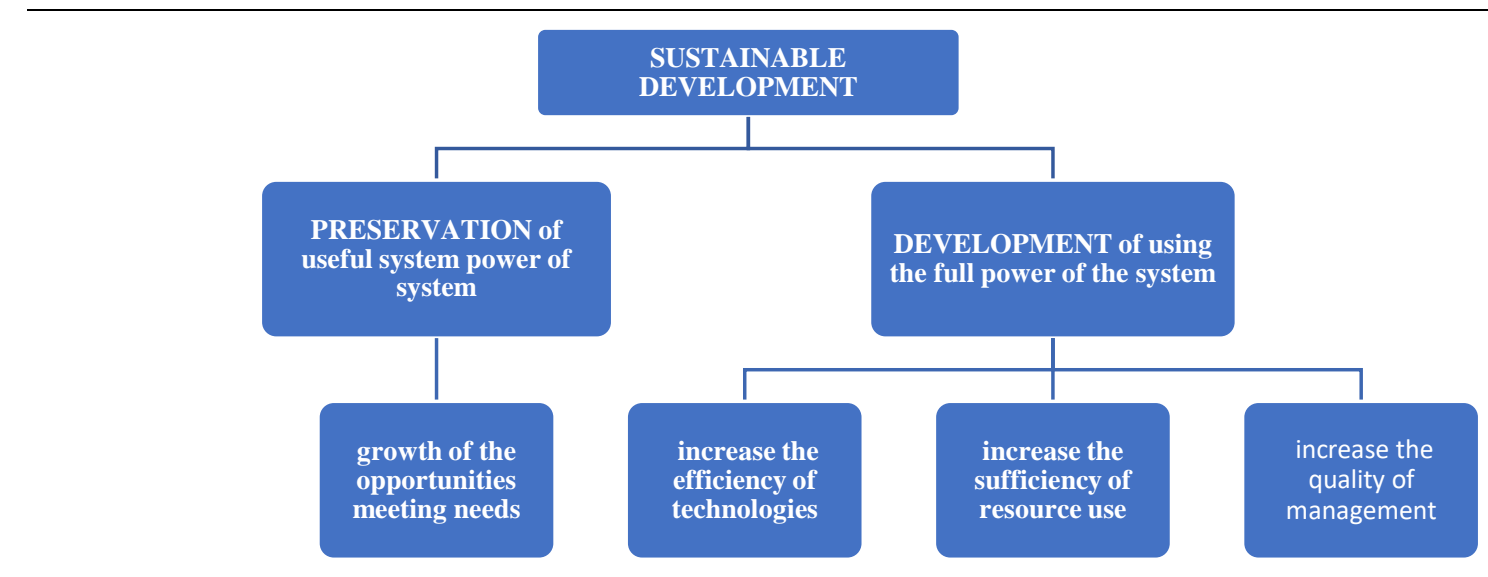

Source: author's construction based on literature review

\section{Fig. 1. Sustainable development definition}

Further development of the concept of sustainable development followed the path of combining three main points of view: economic, social and environmental. Reconciling these different perspectives and translating them into concrete interventions as means of achieving sustainable development is a daunting task, since all three elements of sustainable development must be considered in a balanced way. The considered spatial-temporal power flows approach suggests at the first stage, based on the results of the analysis of power flows, to formulate the level, degree and tendencies of sustainable development of the system. The authors attempted to turn the famous 'temple' of sustainable development 180 degrees.
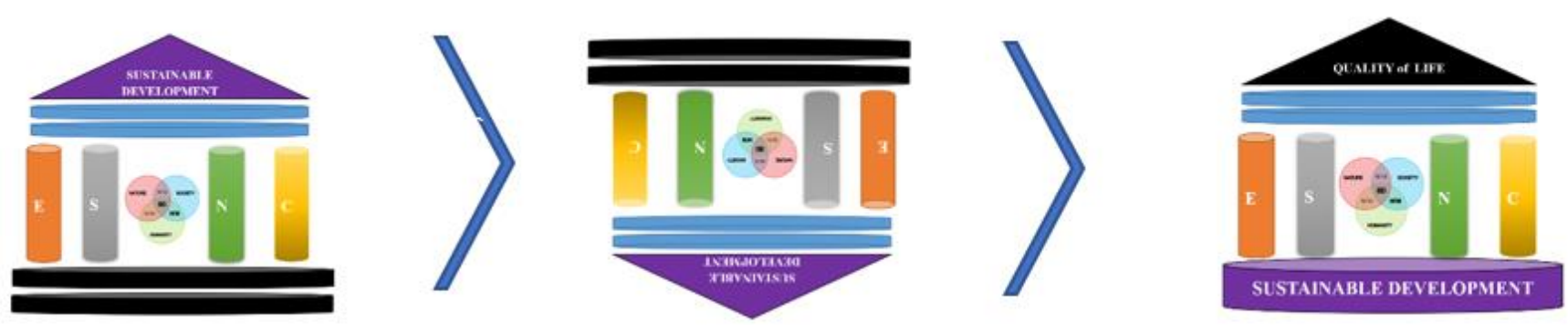

Source: author's construction based on literature review

\section{Fig. 2. Transition of sustainable development 'temple' with pillars}

Thus, the foundation of the 'temple' of sustainable development has transformed into a base for a systematic analysis of the pillars of sustainable development - economy, society and nature. The pinnacle of this temple is the goal of sustainable development of the system - the quality of life (Fig. 2).

\subsection{New approach and research methodology}

Based on the above formulated concepts, the spatial-temporal approach to the analysis of powers and energy flows of the life open systems is based on three main laws (invariants):

1. The law of conservation the power (energy flow) (Kuznetsov, P., 2015), underlying the sustainable development of socio-economic systems (as a life open system). This is the statement that in the system open for energy flows, in time ( $t$ ) the total power $N(t)$ is equal to the sum of the useful power $P(t)$ and the power losses $G(t)$, equations (1). (Fig. 3.):

$$
N(t)=P(t)+G(t)=\text { const }
$$

Where:

$N(t)$ - total power of the system as a result of consumption, in power units Watt;

$P(t)$ - useful power of the system as results of activities, in power units Watt; 
$G(t)$ - power of losses, in power units Watt.

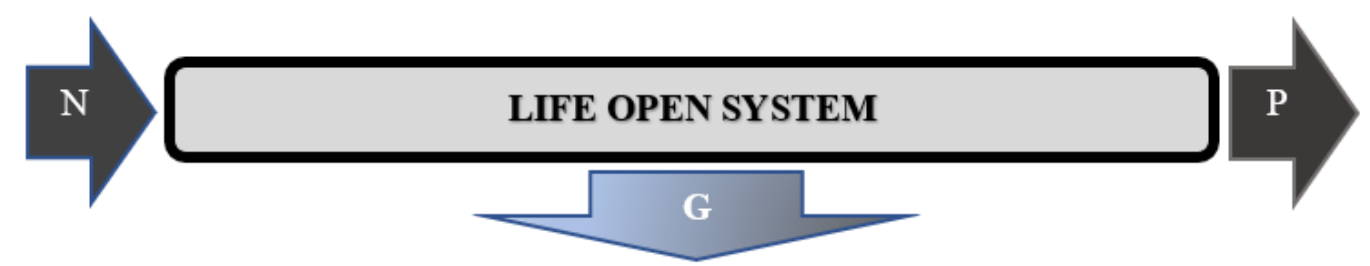

Source: author's construction based on Bolshakov, B. et al, 2019

Fig. 3. The power and flows of energy for life open system

2. The principle of preserve the development (Podolinsky, S., 2004, Vernadsky, V., 2006).

The development of the socio-economic system is preserved, if takes place: if preserving the system quality in spatial-temporal dimension of power and if preserving the continuous increase in the efficiency $\varphi(t)$ of using full power, equations (2):

$$
\Delta \varphi(t)=\frac{d \varphi(t)}{d t}>0, \text { where } \varphi(t)=N(t) / P(t)
$$

3. The principle of sustainable development (in units of power) (Bolshakov, B. et. al., 2019).

Sustainable development is the continuous process of increasing the opportunities to meet the existing constant needs of the system by to the increasing in the efficiency of using the full power of the system reducing losses and without increasing of power consumption in conditions of negative external and internal influences. The introduction of the invariant measure 'power' in the management of sustainable development makes it possible to establish a measurable relationship between needs and opportunities, to build a system of indicators and criteria for sustainable development in accordance with the invariant of the projected class of systems 'man - societies - nature'.

There is a causal relationship between the law of the development of life and the principle of sustainable development of society. This connection is determined by the concept of 'life process' in the system societynature. The society-nature system combines two coupled processes: a) active impact on the environment and $b$ ) the use of the flow of resources by society as a result of this impact. These processes are the essence of the life of society (Bolshakov, B. et. al., 2019) (Fig. 4).
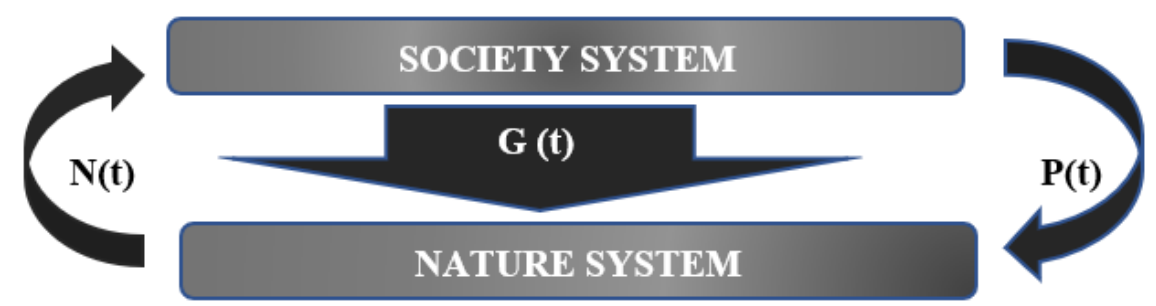

Source: author's construction based on Bolshakov, B. et. al. (2019)

Fig. 4. The society system interaction with the natural environment system

The flow of energy consumed by society $N(t)$ includes all types of fuel and energy-containing resources for machines, mechanisms and technological processes. At the same time, the full power can be used with different efficiency, affecting the real capabilities of the social system. Spending power $P(t)$ (a measure of labour), after the lapse of time $t$ (averaged characteristic time spent on resource extraction), society gets at its disposal a flow of fuel, energy and food resources, measured by the value $N(t)$ - the total power released at the time of primary consumption of energy resources (combustion, eating, etc.). The value of $N(t)$, of course, is many times greater than the value of $P(t)$. The amount of capacity at the disposal of the company is a measure the ability of the system to affect the environment. Demand is the required 
capabilities (capacities) of the system, which are not currently available, but which you need to have in order to maintain development in the future. The problem is the difference between the required and available system capacities. Thus, a system of indicators of sustainable development with an invariant capacity is determined, which characterizes the technological, economic, environmental, social and other capabilities and needs of a complex system. From a methodological point of view, the system is an effective tool for the design of sustainable development in the "man - society - nature" system. The principle (criterion) of sustainable development is the statement that development is supported in the long term, subject to the following conditions, which can be formalized in the form of a system of equations (3), (4), (5), (6):

$$
\begin{aligned}
& P=P_{0}+\frac{d P}{d t} t+\frac{d^{2} P}{d t^{2}} t^{2}+\frac{d^{3} P}{d t^{3}} t^{3} \geq 0, \text { and } \Delta P \geq 0 \\
& \varphi=\varphi_{0}+\frac{d \varphi}{d t} t+\frac{d^{2} \varphi}{d t^{2}} t^{2}+\frac{d^{3} \varphi}{d t^{3}} t^{3} \geq 0, \text { and } \Delta \varphi \geq 0 \\
& G=G_{0}+\frac{d G}{d t} t+\frac{d^{2} G}{d t^{2}} t^{2}+\frac{d^{3} G}{d t^{3}} t^{3}<0, \text { and } \Delta G<0 \\
& N=N_{0}+\frac{d N}{d t} t+\frac{d^{2} N}{d t^{2}} t^{2}+\frac{d^{3} N}{d t^{3}} t^{3} \leq 0, \text { and } \Delta N \leq 0
\end{aligned}
$$

During the research the authors tried to create and use a new system of universal indicators of sustainable development. Under the terms of indicators of sustainable development, the following indicators were taken (Table 1): total consumption of natural resources for a certain time (full capacity), total product (useful capacity), production losses (power losses), quality of human life. This is due to fact that they most

\begin{tabular}{|c|c|c|c|}
\hline Definition & Designation & Unit & Formulae \\
\hline $\begin{array}{l}\text { Needs or opportunities (potential) } \\
\text { (total consumption of resources) }\end{array}$ & $N(t)$ & Watt & $N(t)=\sum_{j}^{k} \sum_{i=1}^{3} N_{i j}$ \\
\hline $\begin{array}{l}\text { Opportunities real } \\
\text { (useful power of system or gross } \\
\text { product produced) }\end{array}$ & $P(t)$ & Watt & $P(t)=\sum_{i=1}^{3} N_{i}(t) \varphi_{i}(t)$ \\
\hline Opportunities lost (power losses) & $G(t)$ & Watt & $G(t)=N(t)-P(t)$ \\
\hline $\begin{array}{l}\text { Opportunities integrated - } \\
\text { quality of life }\end{array}$ & $Q L(t)$ & Watt/people & $Q L(t)=T A(t) U(t) q(t)$ \\
\hline Gross domestic product & GDP & Euro & \\
\hline Population & $M(t)$ & People & \\
\hline Full power efficiency & $\varphi(t)$ & $x$ & $\varphi(t)=P(t) / N(t)$ \\
\hline \multicolumn{4}{|l|}{ Additional indicators } \\
\hline The standard of living & $U(t)$ & Watt/people & $U(t)=P(t) / M(t)$ \\
\hline Normalized time of active life & $T A(t)$ & Year & $T A(t)=($ time of active life $) / 100$ \\
\hline Quality of environment & $q(t)$ & $x$ & $q(t)=G(t) / G(t-1)$ \\
\hline
\end{tabular}
fully reflect the dynamics of the socio-economic development of society.

Table 1

Framework of universal indicators of sustainable development

Source: author's construction based on Bolshakov, B. et. al. (2019)

\section{Results and discussion}

In context of spatial-temporal power flows approach, universal sustainable development indicators were calculated for Latvia. The calculation of the indicators was carried out, using data of Latvian Central 
Statistical Bureau for the period from 2014 to 2019 according formulae in Table 1. The calculation results are presented in the form of table (Table 2 and Table 3) and graphs (Fig. 5, 6, 7, 8).

Integrated changes of needs $\Delta N$ or potential opportunities (total consumption of resources) for Latvia by 2019 have a trend of a negative decrease and the value is below zero (Fig. 5). Integrated changes of real opportunities $\Delta P$ (useful power of system or Gross product produced) for Latvia, by 2019 have a trend of a negative decrease and the value is below zero (Fig. 6). Integrated changes of lost opportunities $\Delta G$ (power losses) for Latvia by 2019 have a trend of a negative decrease and the value is below zero (Fig. 7). Integrated changes of full power efficiency $\Delta \varphi$ for Latvia by 2019 have a trend of a negative decrease and the value is below zero (Fig. 8).

Table 2

Universal indicators of sustainable development

\begin{tabular}{|c|c|c|c|c|c|c|c|}
\hline & Unit & 2015 & 2016 & 2017 & 2018 & 2019 & 2020 \\
\hline$N(t)$ & Watt x 109 & 7.77 & 7.81 & 8.06 & 8.48 & 8.29 & $x$ \\
\hline$P(t)$ & Watt $\times 109$ & 2.27 & 2.20 & 2.20 & 2.32 & 2.35 & 2.29 \\
\hline$G(t)$ & Watt $\times 109$ & 5.60 & 5.58 & 5.62 & 5.74 & 6.14 & 5.99 \\
\hline$Q L(t)$ & Watt x 103/p. & $x$ & 0.85 & 0.85 & 0.89 & 0.87 & 0.94 \\
\hline$G D P$ & Euro x 106 & 23614 & 24561 & 25360 & 26962 & 29143 & $x$ \\
\hline$M(t)$ & People & 1969800 & 1952000 & 1935600 & 1921400 & 1908600 & $x$ \\
\hline
\end{tabular}

\section{Source: Author's calculation based on the data of Central Statistical Bureau of Latvia}

The system of four indicators in accordance with the requirements of sustainable development (equations 3, 4, 5, 6) shows that by 2019 the system of Latvia has a trend towards non-sustainable development (Table 3). A decrease in consumption $(\Delta N<0)$ indicates an extensive development and is the result of a decrease in population, and is not associated with improving the structure of resource consumption and their efficient use.

Table 3

Sustainable development parameters of Latvia in 2019

\begin{tabular}{|l|l|l|l|l|}
\hline \multicolumn{1}{|c|}{ Sustainable development parameters } & $\boldsymbol{\Delta N}$ & $\boldsymbol{\Delta P}$ & $\boldsymbol{\Delta G}$ & $\boldsymbol{\Delta} \boldsymbol{\varphi}$ \\
\hline The requirement of sustainable development, equations & $\leq 0$ & $\geq 0$ & $<0$ & $\geq 0$ \\
\hline The sustainable development parameters for Latvia in 2019 & $<0$ & $<0$ & $>0$ & $<0$ \\
\hline
\end{tabular}

Source: author's construction

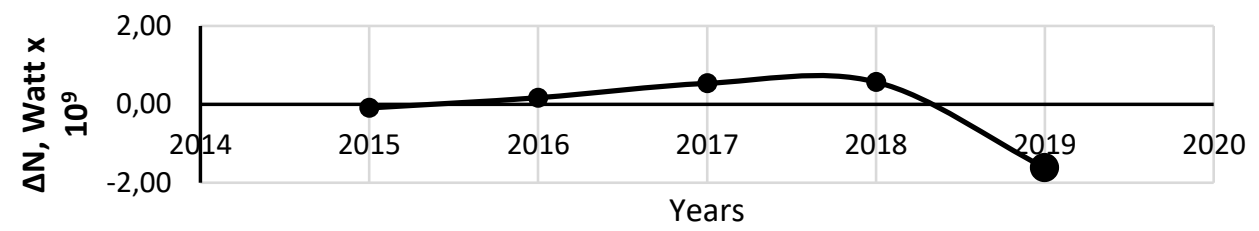

Source: Author's calculation based on Latvian Central Statistical Bureau data

Fig. 5. Integrated changes of needs $(\Delta N)$ or potential opportunities (total consumption of resources) in Latvia for period 2015-2019, in Watt x 109 


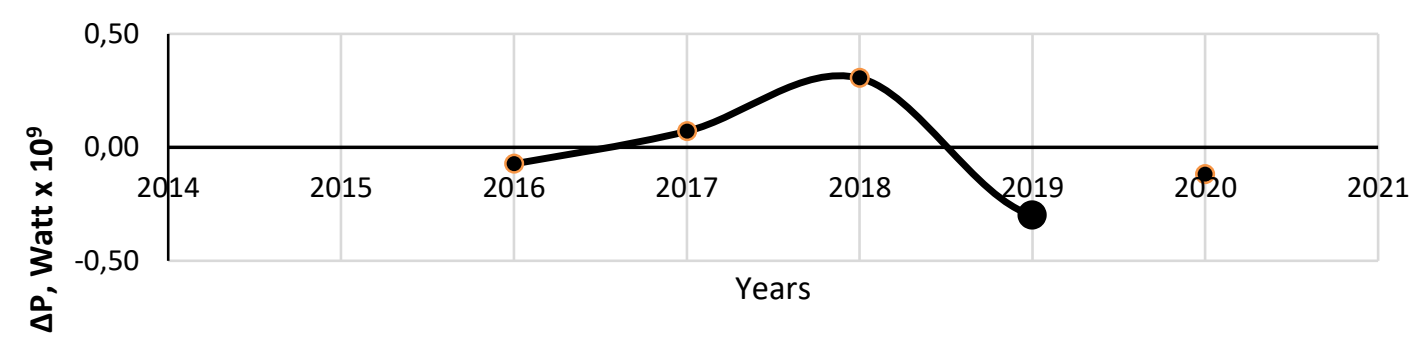

Source: Author's calculation based on Latvian Central Statistical Bureau data

Fig. 6. Integrated changes of real opportunities $(\Delta P)$ (useful power of system or Gross product produced) in Latvia, for period 2016-2019, in Watt $\times 10^{9}$

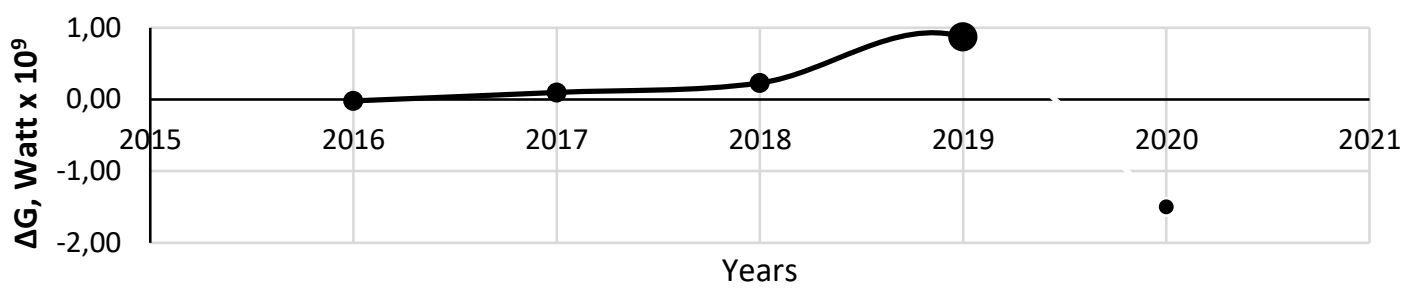

Source: Author's calculation based on Latvian Central Statistical Bureau data

Fig. 7. Integrated changes of lost opportunities $(\Delta G)$ (power losses) in Latvia for period 2016-2019, in Watt $\times 10^{9}$

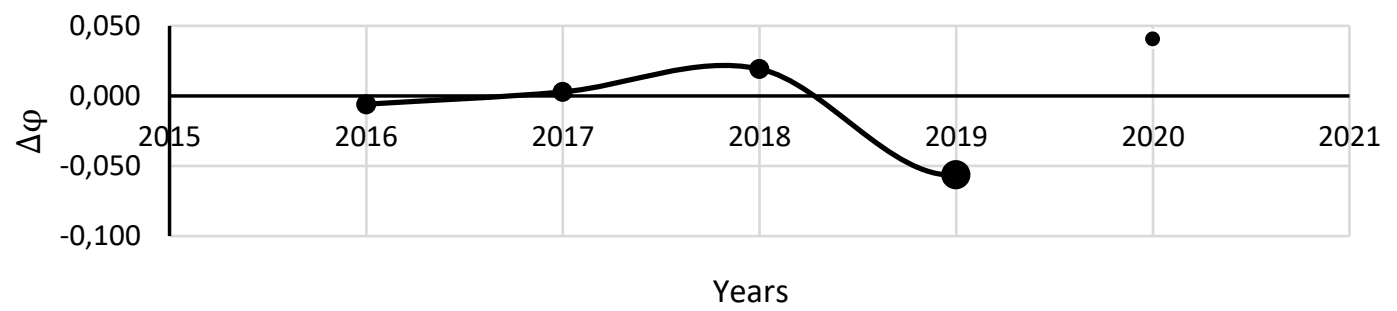

Source: Author's calculation based on Latvian Central Statistical Bureau data

Fig. 8. Integrated changes of full power efficiency $(\Delta \varphi)$ in Latvia for period 2016-2019

\section{Conclusions, proposals, recommendations}

1) The modern requirements related with the development of civilization bring humanity closer to understanding that the socio-economic system is a subsystem and is integrated into the system of nature, and economic processes are natural processes such as biological, physical and chemical processes and transformations.

2) In accordance with the definitions of the natural sciences, all living systems - nature and society are open stable non-equilibrium systems. The main property of energy flows circulating in living systems is their ability to perform external useful work or working capacity.

3) Through labour and scientific thought, a person is included in the biospheres' circulation of matter and energy. This determines the place of labour and reason in the natural-historical process of the evolution of the biosphere. This determines the mission of Human on planet Earth.

4) Sustainable development is a continuous process of preserving the increasing of opportunities to meet the continuous existing needs of the system, expressed in universal units of power. It is transformed the sustainable development into a base for a systematic analysis of the pillars - economy, society and nature. The pinnacle of this temple is the goal of sustainable development of the system the quality of life. 
5) In accordance with the proposed approach, the heterogeneous resources of Latvia were reduced to universal power units, summarized and expressed as a single number. The performed calculations served as the basis for comparing dissimilar indicators, the numerical values of which are not subject to direct summation operations.

6) The values of universal indicators of sustainable development for Latvia for the period from 2015 to 2019 were obtained.

7) The system of four indicators in accordance with the requirements of sustainable development shows that by 2019 the system of Latvia had a trend towards non-sustainable development. A decrease in consumption $(\Delta N<0)$ indicates an extensive development and is the result of a decrease in population, and is not associated with improving the structure of resource consumption and their efficient use.

\section{Bibliography}

1. Agenda 2030, (2015), Transforming our World: the 2030 Agenda for Sustainable Development. Retrieved: https://sustainabledevelopment.un.org/content/documents/21252030\%20Agenda\%20for\%20Sustainable $\% 20 \mathrm{D}$ evelopment\%20web.pdf. Access: 15.11.2020.

2. Aleksejeva, L., Ostrovska, I., Aleksejevs, M. (2020). A Comprehensive Place-Based Approach for Smart Growth in Cross Border Territories. ACM International Conference Proceeding Series DEFIN '20: Proceedings of the III International Scientific and Practical Conference. Retrieved: https://dl.acm.org/doi /abs/10.1145/ 3388984. 3390645. Access:15.11.2020.

3. Bauer E.S. (2002) Theoretical Biology. SPb, pp. 252 c.

4. Bolshakov, B., Karibaev, A., Shamaeva, E. F. (2019). Introduction to the Theory of Management of Novation's with the Use of Spatiotemporal Measures. AIP Conference Proceedings, 2116, 200009., https://doi.org/10.1063/1.5114190

5. Brundtland, G. H. (1987). Our Common Future - Call for action. Environmental Conservation, 14(4), pp. 291294.

6. Daly, H. (1980). Introduction to Essays toward a steady-state economy. In Herman Daly (Ed.), Economics, ecology, ethics: Essays toward a steady-state economy. San Francisco: W.H. Freeman, 1980, 372 p.

7. Hak, T., Janouskova, S., Moldan, B. (2016). Sustainable Development Goals: A Need for Relevant Indicators. Ecological Indicators, 60(1), pp. 565-573.

8. Kuznetsov, P. (2015). Life Development Science, ISBN 978-5-905527-11-1, M.: PAEH., 238 c

9. Lele, S.M. (1991). Sustainable development: A critical review. World Development, 19(6), pp. 607-662.

10. Podolinsky, S. (2004) Socialism and the Unity of Physical Forces, Organization \& Environment, Vol. 17 No. 1 , pp. 61-75, http://pombo.free.fr/podolinsky1881.pdf. Access: 15.11.2010.

11. Pogge, T. (2015). The Sustainable Development Goals: A plan for building a better world? Journal of Global Ethics, 11(1), pp. 56-64.

12. Rio +20 (2012). United Nations Conference on Sustainable Development, Conference report and documents, Rio de Janeiro, Brazil, 20-22 June. Retrieved: https://sustainabledevelopment.un.org/rio20. Access: 15.11.2017.

13. Ropke, I. (2004). The Early History of Modern Ecological Economics // Ecological Economics. Vol. 50. Issue 3-4, pp. 293-314.

14. Shamaeva, E. F. (2019). Novation Management Methodology in Design of Regional Sustainable Development Systems with the Use of Universal Measurable Values, Journal of Advanced Research in Dynamical and Control Systems, 11(8 Special Issue), pp. 329-338.

15. Vernadsky, V. (2006). Essays on Geochemistry \& the Biosphere, tr. Olga Barash, Santa Fe, NM, Synergetic Press, ISBN 0-907791-36-0, pp.86

16. WBCSD (2010). World Business Council for Sustainable Development Vision 2050: The new agenda for business. Retrieved: https://www.wbcsd.org/Overview/About-us/Vision2050/Resources/Vision-2050-The-newagenda-for-business. Access: 15.11.2010. 